\title{
Politique
}

Politique

En collaboration, L'économie fiction : contre les nouveaux économistes, F. Maspero, collection Textes à l'appui, 1982, 235 p.

\section{Benoît Godin}

Numéro 3, hiver 1983

La crise des finances publiques au Québec

URI : https://id.erudit.org/iderudit/040423ar

DOI : https://doi.org/10.7202/040423ar

Aller au sommaire du numéro

Éditeur(s)

Société québécoise de science politique

ISSN

0711-608X (imprimé)

1918-6584 (numérique)

Découvrir la revue

Citer ce compte rendu

Godin, B. (1983). Compte rendu de [En collaboration, L'économie fiction : contre les nouveaux économistes, F. Maspero, collection Textes à l'appui, 1982, 235 p.] Politique, (3), 149-152. https://doi.org/10.7202/040423ar

Ce document est protégé par la loi sur le droit d'auteur. L'utilisation des services d'Érudit (y compris la reproduction) est assujettie à sa politique d'utilisation que vous pouvez consulter en ligne.

https://apropos.erudit.org/fr/usagers/politique-dutilisation/ 
En collaboration, L'économie fiction: contre les nouveaux économistes, F. Maspero, collection Textes à l'appui, 1982, 235 p.

On remet plus facilement en question des idées admises lorsque, confrontées à la réalité en crise, elles ne parviennent plus à rendre compte de l'empirie. C'est aussi cette croissance d'anomalies, entre autres, qui amène les scientifiques à opter pour une nouvelle vision des choses. Voilà le schéma kuhnien que suit parfaitement bien le courant néolibéraliste: en l'absence d'alternatives valables aux déboires des théories keynésiennes, le courant néolibéraliste est parvenu à dominer la littérature économique des dix dernières années.

"L,économie fiction» est une analyse critique des thèses néolibéralistes véhiculées par le monétarisme, la régulation marchande et l'économie de l'offre. Le remède des néolibéralistes étant le désengagement de l'État, les auteurs tenteront ici d'en démontrer la "saveur idéologique». Les nouveaux économistes, ou néolibéralistes, tentent d'expliquer les phénomènes politiques et sociaux par les mécanismes du marché: les décisions sont la somme des choix rationnels des individus, c'est-à-dire des choix orientés vers la maximisation d'utilités personnelles. Cette vision du comportement «économique», définie comme le seul comportement rationnel, comporte plusieurs implications. 
La première, de nous rappeler $\mathrm{R}$. Feydman, est une dévalorisation du politique, complètement conditionné par l'économique: l'État est constitué par l'union des individus en vue de protéger leur propriété. C'est oublier ici que le libéralisme est lui aussi un étatisme en ce sens qu'il détermine les formes sociales du pouvoir.

La deuxième implication théorique, avancée par W. Andreff, est de rendre caduque la notion de «firme» puisque ce qui intéresse les nouveaux économistes ce sont les individus qui la contrôlent, leurs buts et leurs moyens personnels, bref les intérêts de ses membres. Avec cette notion d'intérêts, ou d'utilités, propres à chaque individu mais aussi universels, les nouveaux économistes cherchent à justifier un modèle qui n'existe nulle part ailleurs que dans le discours. C'est ce qu'on appelle généralement une utopie. Le modèle économique classique était un modèle idéal, celui des néolibéralistes un modèle fictif.

L. Gillard va encore plus loin dans l'analyse du courant néolibéraliste en montrant que logiquement ce n'est pas l'individualisme qui est le point de départ mais bien plutôt le principe d'économicité lui-même, c'est-à-dire la capacité de choisir en fonction des disponibilités. C'est ce principe qui conduit aux concepts d'individus et de rationalité, et non le contraire. Le néolibéralisme n'est pas un discours sur la réalité, mais il crée lui-même la société, et c'est pour cette raison qu'il ne peut expliquer pourquoi tel choix plus qu'un autre a été fait:

"parmi l'ensemble des possibles, c'est une seule solution qui survient finalement à chaque instant. Et on peut supposer que c'est la meilleure, faute de quoi l'homme aurait disparu depuis longtemps de la planète. En démontrant que la capacité de choisir produit l'homme, on rend possible une analyse qui fonde l'essence même de la société» (162)

«L'économie fiction» est un des rares ouvrages de critique philosophique et idéologique du courant néolibéraliste. 
Extrêmement bien documenté, tant au niveau de la quantité des références bibliographiques que de leur qualité (période couverte, auteurs cités), cet ouvrage collectif réunit les textes de quatre universitaires français et deux chercheurs du CNRS (Paris). Adoptant une perspective épistémologique, les auteurs déterrent les limites de la théorie ( $R$. Tartarin: Théorie économique de l'histoire), comparent cette dernière à l'empirie (F. Michon: phénomène de chômage) et font ressortir les limites de la méthode (L. Gillard: théorie du consommateur).

Les deux critiques générales qu'ils adressent au modèle concernent la «rationalité » prêtée à tout individu, et l'absence d'une étude des phénomènes de décision dans leurs aspects sociaux. Effectivement, la théorie économique généralise la notion de rationalité: tout individu est supposé maximiser ses intérêts personnels. Pourtant, on sait bien que cette rationalité est toute relative, interne à un système et en rapport aux conditions structurelles qui la constituent (R. Frydman).

Quant à l'absence d'une sociologie dans la théorie, il est vrai que les néolibéralistes refusent de voir dans la politique le lieu d'exercice du pouvoir d'individus aux forces dissymétriques. Cependant, ces critiques contrastent en un sens avec la pertinence du livre puisqu'on peut leur assigner les mêmes limites: elles se veulent universelles, et elles sont teintées d'un parti-pris idéologique.

La critique du «principe d'économicité», ou rationalité économique, rejette tout comportement égoïste des individus, sans même relever certains types de décisions où il s'appliquerait ou certaines composantes d'une décision où il aurait plus de poids. Contrairement à ce que laissent entendre les auteurs, le courant positiviste en science politique est assez éclairant: bien que déficientes à certains égards, les théories de A. Downs et $\mathbf{M}$. Olson ont apporté un élément de plus à l'analyse des phénomènes politiques et sociaux, celui de la prise en 
considération des intérêts individuels à un moment ou l'autre dans les processus de décision. Les limites de ce courant montrent bien qu'il existe d'autres facteurs, mais aussi que les intérêts individuels ne sont pas non plus à négliger.

Ensuite, parler de sociologie n'implique pas nécessairement une analyse marxiste. Acceptant personnellement la grille marxiste, la rigueur scientifique m'empêche tout de même de dénigrer et de passer sous silence les développements récents sur le modèle rationnel. Provenant principalement de la science politique plutôt que de l'économique, ces études tentent maintenant d'incorporer une perspective plus dynamique et sociale dans le modèle, notamment à l'aide de la théorie des jeux, et de se rapprocher des observations empiriques grâce à la vérification du modèle.

$\mathrm{Si}$, pour les auteurs, l'analyse marxiste se prête si bien comme remède à l'analyse économique, c'est peut-être que la théorie marxiste n'est pas si éloignée des thèses individualistes en ce qu'elle définit la société par les intérêts (égoïstes) de classe.

Benoît Godin

Université Laval 